\title{
O POTENCIAL DA EXPERIMENTAÇÃO EM CIÊNCIAS PARA A APRENDIZAGEM DA ATMOSFERA TERRESTRE
}

\author{
THE POTENTIAL OF EXPERIMENTATION IN SCIENCES FOR LEARNING THE \\ EARTH'S ATMOSPHERE
}

DOI: $\underline{\text { 10.23926/RPD.2526-2149.2020.v5.n3.p1802-1816.id894 }}$

\section{Débora de Sena \\ Raposo \\ Graduanda em Licenciatura \\ em Ciências Biológicas \\ (UEA) \\ deborasenara@gmail.com}

Kelly Soares Menezes

Graduanda em Licenciatura

em Ciências Biológicas

(UEA)

ksm.bio16@uea.edu.br

\section{Leandro Barreto \\ Dutra}

Doutor em Educação em

Ciências e Matemática

(UFMT)

Professor na Universidade do

Estado do Amazonas (UEA)

ldutra@uea.edu.br
Resumo: O trabalho trata-se de uma experiência vivenciada durante a disciplina de estágio supervisionado do curso de Licenciatura em Ciências Biológicas da Universidade do Estado do Amazonas. A Sequência Didática aplicada aos alunos do $6^{\circ}$ ano do ensino fundamental abordou o conteúdo da atmosfera terrestre e apoia-se metodologicamente na proposta feita por Zabala (1998). O objetivo consistiu em verificar o potencial da utilização de recursos didáticos e experimentações para aprendizagem das transformações, nas camadas atmosféricas, associadas aos ciclos dos materiais e ao fluxo de energia na Terra. O desenvolvimento se deu em quatro aulas regulares da disciplina de ciências, onde os recursos utilizados contribuíram de maneira significativa, sendo este fato demonstrado pela constante participação dos alunos através da oralidade contextualizando os assuntos. Pode-se perceber que os discentes têm dificuldades de se expressarem textualmente, o que é refletido através de avaliações formais, por vezes insatisfatórias.

Palavras-chave: Contextualização do Conteúdo. Demonstração. Ensino Fundamental.

Abstract: The work is an experience lived during the supervised internship course of the degree course in Biological Sciences of the State University of Amazonas. The Didactic Sequence applied to students of the 6th grade of elementary school addressed the content of the Earth's atmosphere and is methodologically based on the proposal made by Zabala (1998). The objective was to verify the potential of the use of didactic resources and experiments to learn the transformations, in the atmospheric layers, associated with the cycles of materials and the flow of energy on Earth. The development took place in four regular classes of the science discipline, where the resources used contributed significantly, and this fact was demonstrated by the constant participation of students through orality contextualizing the subjects. It can be seen that students have difficulties in expressing themselves verbatim, which is reflected through formal evaluations, sometimes unsatisfactory.

Keywords: Contextualization of Content. Demonstration. Elementary School. 


\section{INTRODUÇÃO}

A educação brasileira, atualmente, ainda pode ser comparada a educação behaviorista/tecnicista do século XX quando se fala em ensino de ciências, pois por vezes utiliza-se de metodologias baseadas na memorização mecânica, de forma verticalizada e com poucos questionamentos sobre o assunto aplicado. $\mathrm{O}$ aluno é levado a aceitação do conteúdo e não à reflexão crítica contextualizada. Segundo Santos (2007), a forma como o ensino de ciências tem caminhado, em sua maior parte, limita-se em memorizações rasas de termos, fórmulas e sistemas classificatórios, em que mesmo que os alunos obtenham êxito ao memorizar, ainda assim não são capazes de aprender o significado de sua linguagem, ou seja, decoram, mas não aprendem.

Alguns fatores parecem colaborar para a manutenção desse quadro, como por exemplo: a imposição de um currículo extenso e denso para ser aprendido em pouco tempo e a falta de formação adequada dos professores em metodologias mais ativas e contextualizadas (KRASILCHIK, 2000; KRASILCHIK, 2004; SANTOS E GRECA, 2006). Além disso, há falta de valorização econômica e social do profissional professor, o qual é submetido a situações estressantes, carga horária excessiva, carga burocrática elevada, relações conflitantes entre professores/estudantes/pais/gestores concomitantemente à percepção que a sociedade tem em relação a sua importância e necessidade ( FERREIRA et al., 2020). Sendo assim, a desmotivação do professor muitas vezes está atrelada ao baixo desempenho escolar dos alunos, os quais não conseguem atingir uma aprendizagem significativa, ainda mais com o conteúdo imposto de forma abrupta, não sendo racionalizado e debatido.

No Ensino Fundamental a faixa etária dos alunos está entre 7 e 12 anos e Piaget (2003) afirma que nesse intervalo de idade os sujeitos estão no período denominado de operações concretas, que em outras palavras significa que possuem a necessidade de objetos ou de situações passíveis de serem manipuladas ou imaginadas de forma sólida, visível e palpável. Essa compreensão parece indicar um caminho possível para que o professor articule estratégias mais adequadas para a aprendizagem de seus alunos. De acordo com Viecheneski (2012) a efetivação de ensino pautado em práticas dialógicas, investigativas e interdisciplinares constituem experiências significativas e desafiadoras para os alunos do Ensino Fundamental.

Neste sentido, as aulas ministradas durante a disciplina de Estágio Supervisionado II do curso de Licenciatura em Ciências Biológicas da Universidade do Estado do Amazonas, objetivaram verificar o potencial da utilização de recursos didáticos e experimentações para 
aprendizagem das transformações, nas camadas atmosféricas, associadas aos ciclos dos materiais e ao fluxo de energia na Terra.

\title{
2 REFERENCIAL TEÓRICO
}

Sabe-se que o ensino de ciências durante muito tempo foi realizado de forma tradicional com a concepção de transmissão do conteúdo e com avaliações priorizando o decorar de nomes científicos e seus conceitos. Em contrapartida Rosito (2008) afirma que a experimentação é uma prática essencial no ensino de ciências, pois não somente colabora com uma melhor compreensão dos processos das ciências como também permite maior interação entre professor e os alunos. Entretanto, para que essas experimentações não sejam apenas atividades práticas e sem sentido, essas devem estar sempre vinculadas com fundamentação teórica, como a autora explicita:

\begin{abstract}
Considero que uma teoria sem embasamento experimental não permite ao aluno uma compreensão efetiva dos processos de ação das ciências. Isto não significa que seja necessário o uso ininterrupto do laboratório nas aulas de ciências, pois muitos conceitos importantes não podem ser construídos experimentalmente nos laboratórios usuais das escolas, eis que exigiria técnicas e aparelhagens muito sofisticadas. No entanto, estes conceitos podem ser trabalhados ativamente pelos alunos por meio da construção de tabelas, gráficos, e pelos dados coletados de experimentos realizado por outros. (ROSITO, 2008, p. 197 - 198)
\end{abstract}

Jean Piaget (2003), em sua teoria do desenvolvimento cognitivo ressalta que o processo de aprendizagem não está relacionado somente ao empirismo e racionalismo, mas também com as interações socioemocionais, onde o sujeito possui papel ativo para/na construção de seu próprio conhecimento. Para Giordan (1999), as aulas experimentais parecem colaborar para despertar essa postura ativa dos alunos despertando o interesse devido ao caráter motivador e lúdico da experimentação e, como apontam Galiazzi e Gonçalves (2004) ainda podem colaborar como estratégia eficaz para o processo de contextualização dos conceitos científicos.

De acordo com a nova Base Nacional Comum Curricular (BRASIL, 2019) é imprescindível que os alunos sejam progressivamente estimulados e apoiados no planejamento e na realização cooperativa de atividades investigativas, não sendo estas baseadas apenas em mera manipulação de objetos ou realização de experimentos em laboratório, mas organizadas a partir situações de aprendizagem, partindo de questões que sejam desafiadoras e que estimulem o interesse e a curiosidade científica dos alunos e possibilitem definir problemas, levantar, analisar e representar resultados.

Chaves e Hunshe (2014) defendem a ideia da realização de experimentações sem a necessidade de espaços escolares específicos, como os laboratórios, pois existem atividades 
experimentais que podem ser feitas em qualquer sala de aula com materiais simples e inclusive de baixo custo. A importância dessa movimentação está também para além dos materiais laboratoriais, mas no despertar discussão, reflexão e motivação nos aprendizes.

Diversos autores vêm contribuindo com pesquisas que apontam que para melhoria do ensino de ciências no Brasil uma incorporação efetiva de práticas experimentais contextualizadas e interdisciplinares é necessária para a construção de um pensamento críticocientífico (DELIZICOIV e ANGOTTI, 2000; ANDRADE e MASSABNI, 2011; BASSOLI, 2014).

Obviamente essas experimentações não são feitas isoladamente, sem o contexto teórico, pois não basta movimentar objetos e corpos, o objetivo inclui também a movimentação de ideias e conceitos e, para isso todas as atividades práticas investigativas devem integrar a uma sequência de atividades que tenham sentido no contexto que estão inseridos.

\section{Metodologia}

A pesquisa trata-se de um subprojeto dentro do projeto denominado "A universidade na escola e o ensino de ciências e biologia: uma prática de aprendizagem baseada em projetos", possuindo Certificado de Apresentação de Apreciação de Ética (CAAE) de numeração 69623317.5 .0000 .5016$.

A mesma pode ser caracterizada como qualitativa e de campo e apoiou-se nos princípios da Sequência Didática (SD), que segundo Zabala (1998, p.18) é "[...] um conjunto de atividades ordenadas, estruturadas e articuladas para a realização de certos objetivos educacionais, que têm um princípio e um fim conhecido, tanto pelos professores como pelos alunos". Para este autor a prática pedagógica necessita de uma organização e estrutura bem articulada entre si, que ganhem sentido para o objetivo que se pretende alcançar. Para esse desenvolvimento o pedagogo sugere que se tenha em mente duas perguntas norteadoras: para quê educar? E para quem ensinar? Segundo o autor essas seriam as perguntas chaves para o início da organização do processo de ensino-aprendizagem de maneira reflexiva.

$\mathrm{O}$ autor sugere o desenvolvimento de uma SD, consistindo em levantamento de conhecimentos prévios, apresentação do conteúdo, contextualização, análise e discussão em torno de problemas, soluções e sistematização.

O tema selecionado pela professora regente da escola para que fosse desenvolvido uma SD foi a Atmosfera terrestre, que segundo a docente além de constar no plano de ensino escolar, os discentes apresentavam dificuldades de aprendizagem, pois trata-se de um conteúdo abstrato, 
visto que envolve medidas de longas distâncias, de gases e camadas atmosféricas que não são vistas a olho nu. O desafio foi preparar uma estratégia contextualizada e que de algum modo pudesse cooperar para a visualização do que normalmente não é visto.

A Sequência Didática foi desenvolvida no total de quatro aulas no horário semanal normal dos alunos, na disciplina de Ciências. A intenção era abordar o conteúdo dentro das etapas elaboradas por Zabala (1998) e que abordasse desde as camadas atmosféricas e sua composição até sua importância para o meio ambiente e seres vivos.

A primeira aula: Aplicação de uma atividade escrita (Figura 1), feita em dupla, sobre as camadas atmosféricas para averiguar os conhecimentos prévios dos alunos sobre o conteúdo específico e, logo em seguida, algumas perguntas foram feitas a fim de sondar o que pensavam a respeito da temática, como por exemplo, "o que tem acima do céu? Vocês já imaginaram se existe alguma coisa depois das nuvens? Estamos em que planeta? O que é o espaço?”. Os alunos responderam às perguntas, respetivamente, com as seguintes afirmações "Mais nuvem", “Não, professora”, "Planeta Terra, né!?”, “Gás”. Após essa dinâmica introdutória iniciou-se os conteúdos teóricos, propriamente dito, através de um projetor de slides respondendo às perguntas que foram feitas em diálogo com os alunos presentes.

Aula 2: Esta aula enfatizou a importância do gás oxigênio e do gás carbônico para a atmosfera, utilizando-se de demonstração sobre o processo de combustão. Inicialmente, foi reaplicada a mesma atividade da Aula 1, com a mesma dupla, a fim de verificar o grau de aprendizagem daquele conteúdo já abordado, através da quantidade de erros e acertos das questões. Após a realização da atividade, a aula seguiu com a demonstração prática de combustão do oxigênio, através de uma vela e um copo.

No experimento, realizado pelas professoras estagiárias, a vela foi fixada na ponta da mesa e acesa, posteriormente, um copo de vidro foi colocado sobre a vela, sendo este maior em largura e comprimento. Ocorreu o consumo do oxigênio presente no espaço dentro do copo pela vela, e a mesma apagou-se comprovando a utilização do oxigênio no processo de queima (combustão). De acordo com Zabala (1998, p.55) a demonstração atuou como "atividade motivadora relacionada com uma situação conflitante da realidade experiencial dos alunos”. 
Figura 1 - Atividade sobre camadas atmosféricas

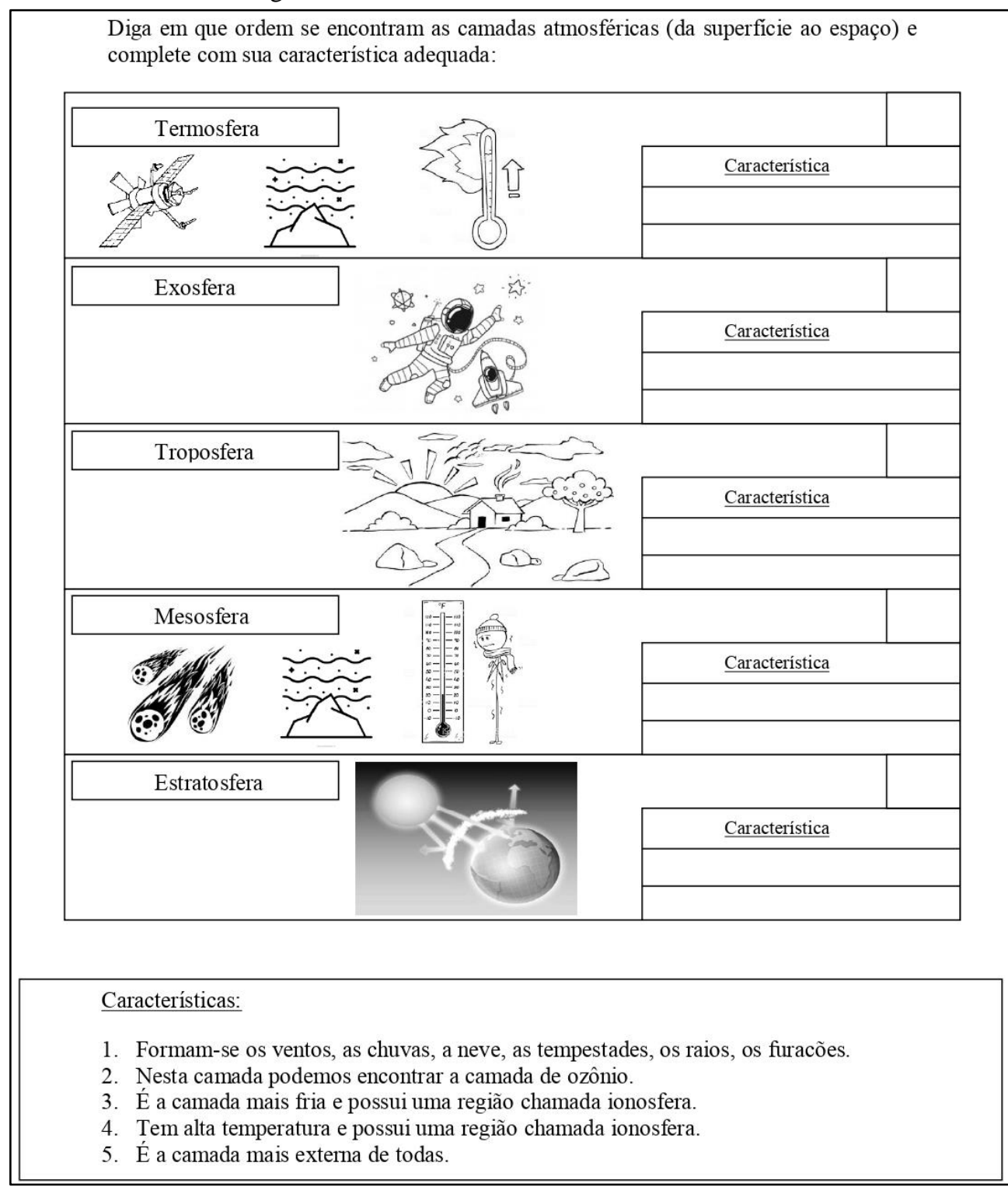

Aula 3: Começou com uma revisão sobre o assunto da aula anterior e em seguida realizou-se uma nova demonstração com utilização de um copo com água gelada. Devido à baixa temperatura da água, em estado líquido, em comparação com o vapor de água atmosférico, o vapor d'água se condensou em forma de gotículas ao redor do copo, possibilitando comprovar, aos alunos, a sua existência na atmosfera. Posteriormente a demonstração, o conteúdo teórico foi abordado, referindo-se ao vapor de água, em seguida, foi iniciada a explicação sobre os respectivos assuntos: gás nitrogênio e seu ciclo; gases nobres.

Aula 4: Continuação da etapa de apresentação do conteúdo acrescida dos tópicos sobre o efeito estufa, aquecimento global e propriedades do ar. Os tópicos efeito estufa e aquecimento 
global foram ministrados com o auxílio de slides e em seguida foi passado um vídeo ${ }^{1}$ exemplificando o efeito estufa, as causas do agravamento do aquecimento global e as maneiras de colaborar com a solução dessa problemática.

Realizou-se nova demonstração sobre pressão atmosférica fazendo uso de um garrafão de água seco, álcool e fósforo. Inicialmente foi adicionado $5 \mathrm{ml}$ de álcool 46,3 INPM dentro do garrafão de água seco e este foi chacoalhado, posteriormente o mesmo foi invertido para o escoamento do álcool de seu interior e posicionado em cima da mesa com a abertura voltada para cima. Em seguida, um fósforo foi aceso e jogado dentro do garrafão, ocasionando uma mini explosão. Quando a explosão terminou, rapidamente o garrafão foi tampado com a mão e este murchou.

Antes da demonstração, sem prévias do que iria ocorrer, foram realizadas algumas perguntas aos alunos, como "O que acontecerá com o garrafão se colocamos um pouco de álcool e jogar um fósforo aceso dentro? Por quê? Como acontece?". Então, durante a experiência, estes ficaram perguntando-se como era possível ocorrer tal fato e puderam criar suas próprias hipóteses.

Para finalizar a aula, foi proposta uma prova-atividade escrita, composta por 5 perguntas: "o que aconteceu com o garrafão no experimento? Por quê?"; "explique o que é efeito estufa."; "como os animais obtêm as substâncias de nitrogênio se não conseguem utilizar o que está presente na atmosfera?"; "qual a importância dos gases nobres para nossa vida?" e "o que é combustão e o que é necessário para que ocorra esse processo?". As questões abordaram todo o tema, sendo assim utilizadas para analisar o conhecimento adquirido pelos alunos, visando observar a sistematização e aprendizagem do conteúdo.

\section{Resultados}

Foram avaliadas 12 duplas de alunos nas aulas 1 e 2, consistindo no total de 24 alunos e na aula final, Aula 4, foram avaliados individualmente o total de 31 alunos. A turma era composta pelo total de 34 alunos matriculados regularmente, porém há variações devido faltas e desistências. Cada aula durou em torno de 1 hora, tempo regular da escola. A Aula 1 consistiu primeiramente no contato inicial com a turma, onde foi possível conhecê-la e ter uma ideia sobre comportamento e participação dos alunos. Estes mostraram-se agitados e bastante falantes, com isso, pode-se constatar uma grande participação da turma. Além disso, foi aplicado um exercício inicial sobre o conteúdo a ser abordado, servindo este como sondagem.

\footnotetext{
${ }^{1} \mathrm{O}$ vídeo utilizado pode ser acessado no link https://www.youtube.com/watch?v=e054mplj5nw
} 
Na Aula 2 os exercícios foram reaplicados e avaliados através de nota, onde cada resposta certa equivalia a 2,0 e sua somatória totalizava 10,0 . Foi possível observar uma melhora no desempenho médio da turma, porém, com a análise individual de cada dupla, podese observar que as duplas de números 2 e 6 se mantiveram com mesma nota, 6,0 e 2,0 respectivamente, e a dupla 3 apresentou uma nota inferior, onde, na primeira aplicação obteve nota 10,0 e na reaplicação nota 6,0 . Destacaram-se positivamente as duplas 1, 4, 5 e 10. (Figura 2).

Figura 2 - Atividade sobre camadas atmosféricas

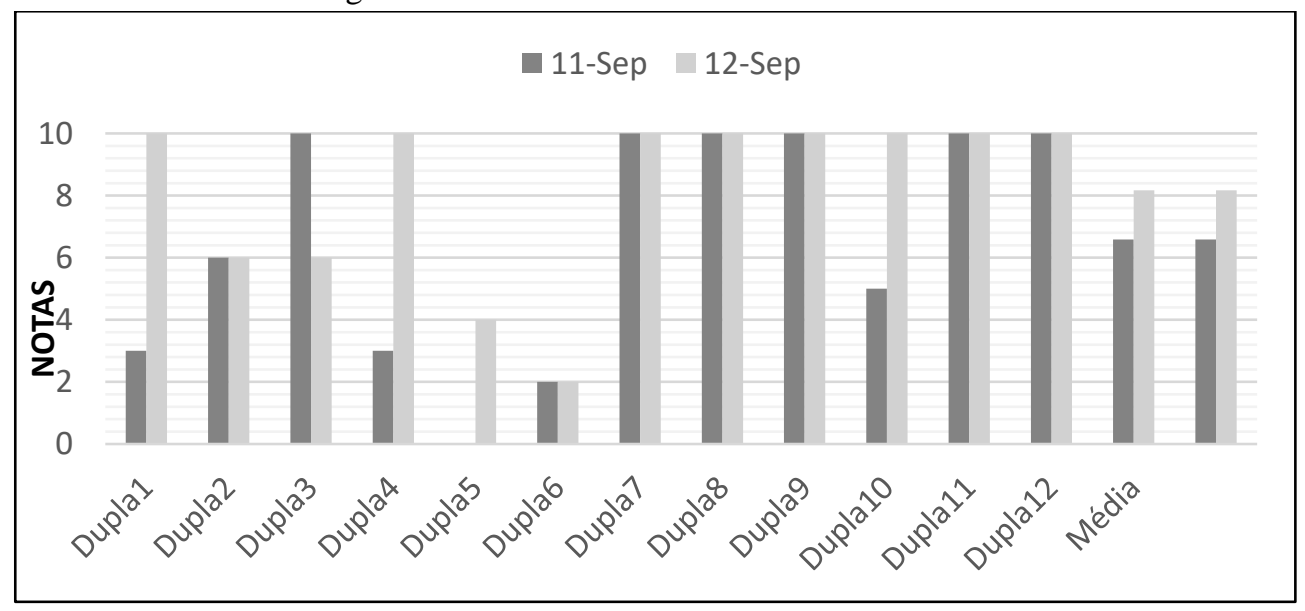

Fonte: Autores.

Pode-se perceber, levando em consideração a partir de 50\% de acertos na atividade, que $60 \%$ dos alunos tinham um conhecimento prévio sobre o assunto em questão. A dupla 6 foi a mais preocupante uma vez que apresentou média 2 em ambas as aulas, talvez por falta de compreensão sobre o exercício ou dificuldade em acompanhar a turma e finalizar a atividade no tempo estipulado de 15 minutos.

Finalizando a atividade, foi realizado a demonstração da vela com um copo e, o interessante de se notar foi que, apesar de ser uma experiência muito simples, os alunos fixaram sua atenção, demonstrando interesse e realizando um grande esforço para visualização. $O$ fato remete o quanto o visual, a demonstração e a realização de experimentos, fazem diferença na aula.

Dessa forma é demonstrado que a percepção pelos sentidos faz com que ocorra assimilação de conhecimento, mostrando assim o poder dos sentidos e percepções na aprendizagem. Comenius (2001) afirma que nada está na mente sem que o avanço não fosse dado na sensação. 
provar - o gosto, o tato está disponível - através do sentido do tato. A partir desses itens é imediatamente possível perceber alguns sentimentos, deixá-los aproveitar vários sentidos ao mesmo tempo. (1982 apud KONSTANTINOVA E ALCÂNTARA, 2016, p.222).

Em seguida foi perguntado aos alunos o que havia acontecido, e muitos responderam com tom irônico “acendeu uma vela né, professora!”, ou seja, algo que para eles era óbvio, porém ainda não haviam questionado como funcionava o processo e o porquê de a vela acender. Posteriormente, foi posto um copo sobre a vela e foi realizada a seguinte pergunta "Por que a vela se apagou?". Frente ao problema, muitos não souberam explicar de forma clara, apenas afirmaram "o ar foi abafado, professora" ou até mesmo "apagou por causa do copo". A partir dessa pergunta e das respectivas respostas, as quais os alunos tiveram que imaginar soluções para o que tinham visto e assim assimilar de forma reflexiva o acontecimento, o conteúdo sobre a combustão e a importância do gás oxigênio para os seres vivos foi abordado.

A contextualização, segundo Rodrigues e Amaral (1996) significa trazer a própria realidade do aluno como o próprio contexto de ensino do conteúdo, interferindo de maneira positiva na aprendizagem, auxiliando e facilitando o processo. Diversos exemplos em sala de aula reforçaram tal afirmação, como quando foi mencionado um momento da infância da professora a qual tentou criar insetos denominado popularmente como "soldadinhos" (Membracis sp.), em sacos plásticos fechados, os quais morreram após algumas horas. Os "soldadinhos", como já dito, são insetos, sugadores e que em sua grande maioria vivem em gravioleiras. São muito comuns na região norte do Brasil e bastante conhecidos. Então, o contexto dos alunos e também da professora foi utilizado para explicar sobre a importância do oxigênio para os seres vivos, facilitando o processo de assimilação.

$\mathrm{Na}$ Aula 3 o ciclo do nitrogênio foi abordado. Esse conteúdo, por se tratar de estruturas químicas micromoleculares, parece ser de difícil compreensão pelos discentes. Talvez não faça sentido trabalhar esse conteúdo tão abstrato e rico em detalhes agora no sexto ano, visto que conteúdos dessa natureza ainda não foram abordados nessa idade, como por exemplo, a química que só é vista no nono ano, ou seja, três anos depois. Essa dificuldade na compreensão desse conteúdo foi uma surpresa durante a aplicação da SD, podendo ser explicada por Piaget (2003), o qual afirma que o sujeito tem a capacidade de organizar o mundo de forma lógica, não se limitando mais a uma representação imediata, mas ainda depende do mundo concreto para desenvolver a abstração. Portanto, há conteúdos difíceis de explicar de forma totalmente concreta, devido os mesmos terem bases abstratas, como é o caso da química do ciclo do nitrogênio. 
O tópico sobre gases atmosféricos foi lecionado enfatizando a importância dos gases nobres para o funcionamento de vários equipamentos do dia-a-dia, como por exemplo, o gás hélio para encher balões de festa, o gás neônio utilizados em lâmpadas de neon e o gás xenônio usado na lâmpada de faróis de veículos.

A Aula 4 foi uma aula rápida e os alunos demonstraram grande interesse no vídeo passado em sala de aula, fizeram silêncio e mantiveram-se atentos. Após o término do vídeo foram feitas algumas perguntas, como "quais as consequências do aquecimento global em nosso planeta?" e "o que podemos fazer para diminuir o agravamento do aquecimento global?". Souberam responder muito bem, alguns ressaltaram que "se continuar assim, a temperatura da terra vai subir e pode até ninguém mais morar aqui” outros falaram de que podíamos contribuir “economizando energia e usando ônibus”, logo em seguida a aula continuou com a ministração do conteúdo sobre propriedades do ar.

O experimento realizado ao final do conteúdo fez com que os alunos ficassem entusiasmados com o resultado, pedindo para refazer várias vezes. Quando o experimento foi finalizado, foram feitas algumas perguntas como "o que aconteceu com o garrafão? e por que aconteceu?". Foi gratificante perceber que os alunos puderam conectar todos os assuntos das aulas anteriores para responderem às perguntas propostas, onde com entusiasmo foram levantando a mão e respondendo sem esperar que fosse sua vez com frases do tipo "O garrafão murchou porque teve a combustão e acabou todo o oxigênio de dentro e pressão no garrafão mudou e com isso murchou” " que legal, o garrafão murchou!" "Aconteceu uma explosão e o garrafão murchou" "O oxigênio de dentro do garrafão acabou” "Professora, foi por causa da queima”, “a pressão da atmosfera é maior porque tem oxigênio”. Em seguida foi explicado o experimento e após isso, foi realizado uma prova escrita e individual sobre os conteúdos abordados nas quatro aulas.

A correção da prova escrita teve impasses devido à dificuldade de expressão dos alunos em escrever, sendo estes, melhores em explicar através da oralidade. Além dos erros ortográficos, suas respostas mostraram-se incompletas e termos muito vagos foram utilizados em suas respostas.

\footnotetext{
Atentos ao fato de que a habilidade de escrita é um processo contínuo que evolui com a idade, acelera-se, torna-se firme, abranda-se e adquire regularidade, pesquisadores como Bazi (2000) e Sisto (2001) alertam que há que se ter cautela ao avaliar suas dificuldades. Segundo Sisto (2001), erros como inventar palavras e omitir, confundir, inverter algum som ou letra são relativamente comuns no início dessa fase de aprendizagem, adquirindo um sentido de dificuldade de aprendizagem somente após uma experiência escolar prolongada. (SUEHIRO, 2006, p. 6)
} 
Deste modo, isso refletiu na média da turma, sendo esta de 4,9. Caso a avaliação geral fosse utilizada como prova final, sendo a média da escola 7.0 pontos, apenas 38,7 \% dos alunos estariam aprovados enquanto 61,3\% não teriam aprovação sem recuperação.

Foi notório que os alunos do Ensino Fundamental ainda apresentam uma grande dificuldade na escrita, em escrever de maneira correta aquilo que eles sabem, por mais que os seus conceitos estivessem certos, sua forma de se expressar não era suficientemente coerente. Observou-se que esses problemas poderiam ser explicados por talvez os alunos exercitarem pouco esse processo de transpor suas ideias para a escrita, dificultando assim o processo de avaliação e até de aprendizagem em outras disciplinas.

A aquisição da linguagem escrita depende da mediação de quem já domina essa linguagem. Assim, só se compreende a aprendizagem na relação com o outro que já faz uso desse conhecimento. Nesse processo o papel do professor é de exercer uma ação intencional no sentido de levar o aluno a refletir sobre esse objeto do conhecimento através de ações de explicitar, discutir, traduzir, conceituar, mostrar, exemplificar o ato de ler e escrever. (CURITIBA. Secretaria Municipal da Educação, 1996, p. 33)

Quando avaliado a relação de acertos por questão (Figura 3), é notório que as questões que obtiveram maior quantidade de acertos entre todos os alunos foram aquelas sobre o experimento e do processo de combustão, no qual os dois conteúdos foram utilizados a realização de uma demonstração para sua explicação, um com o garrafão e o outro com a vela, constatando assim que o processo de aprendizagem dos alunos ainda requer muito do concreto para um bom aprendizado.

Figura 3 - Análise individual por questão

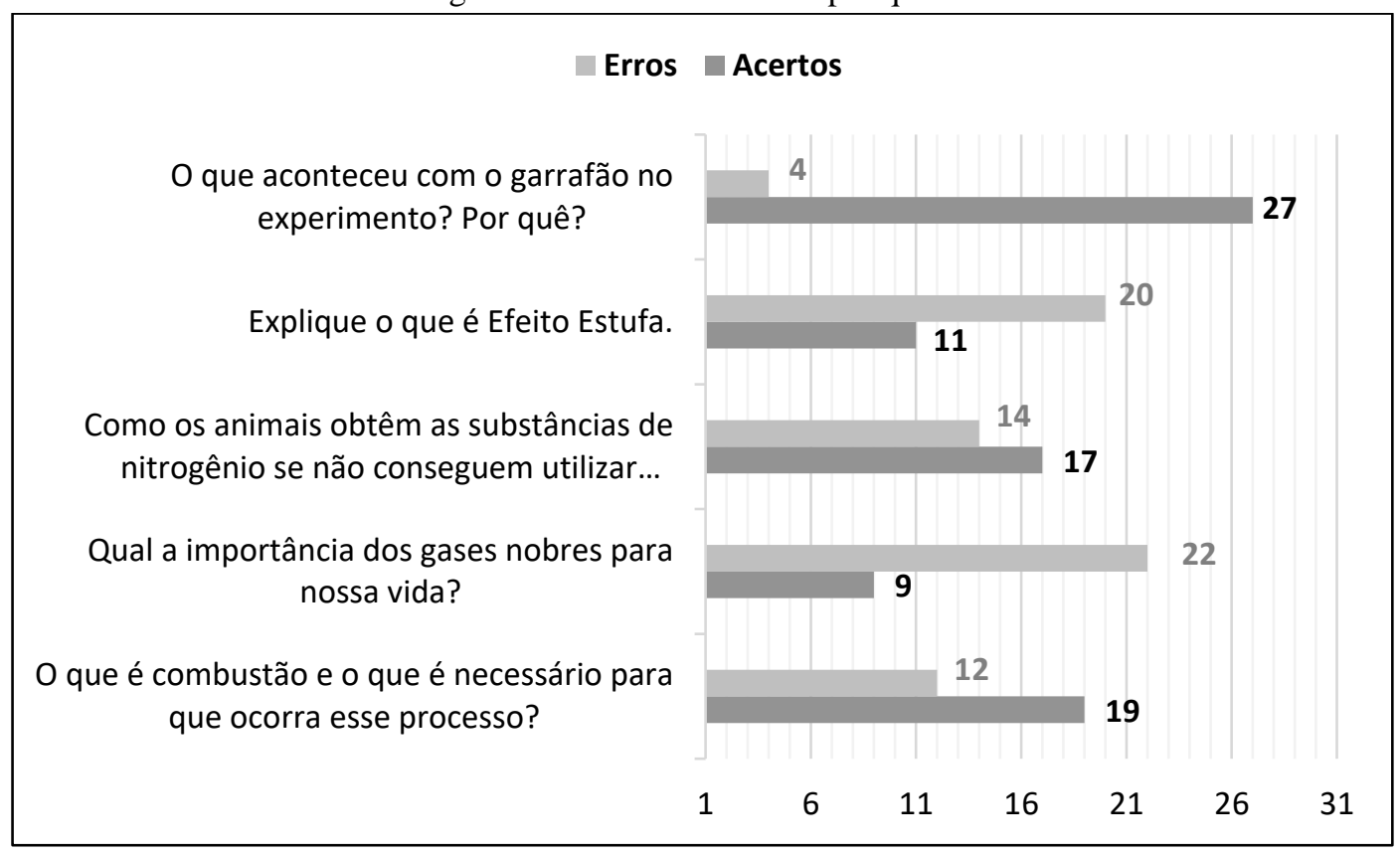

Fonte: Autores (2018). 
As questões que apresentaram maior quantidade de erros entre os alunos foram as questões sobre o efeito estufa e os gases nobres, onde, na ministração dos dois conteúdos foram utilizados primeiramente analogias para a sua explicação, porém os alunos não conseguiram assimilar de maneira geral o conceito, mas se agarraram ao exemplo, demonstrando uma compreensão literal do dito e reafirmando a concepção piagetiana sobre a aprendizagem do concreto.

Durante a explicação do conteúdo sobre o efeito estufa, foi utilizado a demonstração de uma estufa para assim exemplificar que o mesmo acontecia com o nosso planeta, entretanto, nas questões sobre esse assunto as respostas vieram "O efeito estufa é uma câmera de vidro que o sol entra e faz as plantas crescerem" ou "É quando o sol entra no vidro e esquenta e as plantas crescem".

Em cada aula foi possível notar a necessidade dos alunos em associar os conteúdos com a realidade deles, com algo que haviam vivenciado, como exemplo, a frase dita em relação a presença de oxigênio "Professora, é por isso que quando alguém sobe em uma montanha não consegue respirar, eu vi na televisão" e em relação às camadas atmosféricas "o meteoro não consegue chegar na terra porque ele quebra".

\section{CONSIDERAÇÕES FINAIS}

A realização de uma Sequência Didática para alunos do $6^{\circ}$ ano do Ensino Fundamental caracterizada por aulas teóricas expositivas atreladas a experimentos fez com que estes pudessem compreender o conteúdo "A atmosfera", mesmo sendo abstrato e de difícil associação com a sua realidade. Podemos observar que a Sequência Didática por apresentar uma linha lógica sobre o conteúdo, com início, meio e fim possibilitou a interligação entre os conceitos explanados nas aulas.

Em relação a atitude dos alunos devido a metodologia aplicada, estes se apresentaram empolgados e participativos uma vez que as aulas foram dinâmicas e diferenciadas, as quais possibilitaram que conseguissem fazer conexões do seu dia-a-dia com o conteúdo explanado. Além disso, tais fatos fizeram com que o professor se motivasse ainda mais para conseguir explorar o conteúdo da melhor forma possível.

As atividades experimentais demonstrativas realizadas durante as aulas foram de extrema significância para a aprendizagem dos alunos. Tanto a demonstração da vela acesa sobre a mesa quanto a sobre pressão atmosférica fazendo uso de um garrafão de água seco, chamaram atenção dos alunos despertando curiosidade e fazendo com que estes viessem a 
perguntar e participar ativamente da aula por vontade própria. Porém, apesar da compreensão dos alunos, deve-se levar em consideração ao abordar um conteúdo abstrato a idade do aluno o qual pretende-se ensinar, pois a capacidade cognitiva, variante com a idade, faz com que os alunos apresentem dificuldade em tornar lógico algo que não lhe é apresentado ao toque.

Portanto, pode-se concluir que além da implantação de metodologias expositivas, experimentais, ou seja, atrativas, é preferível que o conteúdo imposto seja de acordo com a idade e habilidade apresentada pelos alunos alvos.

\section{REFERÊNCIAS}

ANDRADE, Marcelo Leandro Feitosa; MASSABNI, Vânia Galindo. O desenvolvimento de atividades práticas na escola: um desafio para os professores de ciências. Revista Ciências e Educação, v.17, n. 4, 2011.

BAZI, Gisele A do Patrocínio. As dificuldades de aprendizagem em leitura e escrita e suas relações com a ansiedade. 2000. 112 f. São Paulo: Dissertação (Mestrado) - UNICAMP, Campinas, 2000.

BASSOLI, Fernanda. Atividade práticas e o ensino-aprendizagem de ciência (s): mitos, tendências e distorções. Revista Ciências e Educação, v. 20, n. 3, p. 579-593, 2014.

BRASIL. Base Nacional Comum Curricular (BNCC). Educação é a Base. Brasília, MEC/CONSED/UNDIME, 2019.

BRUNER, Jerome S. O Processo da educação Geral. $2^{a}$ ed. São Paulo: Nacional, 1991.

COMENIUS, Johannis Amos. Didactica Magna. eBooksBrasil, 2001.

CURITIBA. Currículo Básico: "Compromisso permanente para a melhoria da qualidade do ensino na escola pública”. Secretaria Municipal da Educação, 1996.

CHAVES, Jossuele Maria Fagundes; HUNSCHE, Sandra. Atividades experimentais demonstrativas no ensino de Física: panorama a partir de eventos da área. TCC. Universidade Federal do Pampa. Rio Grande do Sul, 2014

DELIZOICOV, Demétrio; ANGOTTI, José André. Metodologia do Ensino de Ciências. São Paulo: Cortez, 2000

FAGUNDES, Carlos Magalhães de. Os novos desafios para a educação especial. São Paulo: Ação Educativa, 2001.

FERREIRA, Valeria Oliveira; BÓ, Adriane dal; AMARAL-ROSA, Marcelo Prado; LIMA, Valderez Marina do Rosário; RAMOS, Maurivan Guntzel. A desvalorização do professor: percepções de professores participantes de um programa de Pós-Graduação em Educação em Ciências e Matemática. Revista Thema, v. 17, n. 1, p. 243-255, 2020. 
FOUREZ, Gérard. Crise no Ensino de Ciências: investigações em ensino de ciências. Revista Investigações em Ensino de Ciências, v. 8, n. 2, 2003.

GALIAZZI, Maria do Carmo.; Gonçalves, Fábio Peres. A natureza pedagógica da experimentação: uma pesquisa na licenciatura em Química. Química Nova, v.27, n.2, p.326331, 2004.

GIORDAN, Marcelo. O papel da experimentação no ensino de ciências. Química Nova na Escola, v. 10, n. 10, p. 43-49, 1999.

KRASILCHIK, Myriam. Reformas e Realidade: o caso do ensino de Ciências. São Paulo em Perspectiva, v. 14, n. 1, 2000.

KRASILCHIK, Myriam. Prática de ensino de biologia. São Paulo: Editora da Universidade de São Paulo, 2004.

KONSTANTINOV, Nikolaj Aleksandrovič; MEDYNSKIY, Evgenij Nikolaevič; ŠABAEV, Mariâ Fedorovna. Istoriya pedagogiki. M., 1982.

KONSTANTINOVA, Elena.; ALCANTARA, Marlon Cesar. A influência de recursos visuais na assimilação de conhecimentos nas aulas de física. Multiverso, v.1, n.2, 219-228, 2016.

PIAGET, Jean. Seis estudos de psicologia. 24 ed. Rio de Janeiro: Forense Universitária, 2003.

RODRIGUES, Cármen Lúcia; AMARAL, Marise Basso. Problematizando o óbvio: ensinar a partir da realidade do aluno. In: CONGRESSO DA ASSOCIAÇÃO NACIONAL DE PÓSGRADUAÇÃO E PESQUISA EM EDUCAÇÃO, 19, 1996. Anais... Caxambu, 1996, p. 197.

ROSITO, Berenice Álvares. O ensino de Ciências e a experimentação.Construtivismo e ensino de Ciências. Porto Alegre: Edipucrs, p.195-208, 2008.

SANTOS, Flávia Maria Teixeira dos; GRECA, Ileana Maria. A pesquisa em ensino de ciências no Brasil e suas metodologias. Ijuí: Unijuí, 2006.

SANTOS, Wildson Luiz Pereira dos. Educação científica na perspectiva de letramento como prática social: funções, princípios e desafios. Revista Brasileira de Educação, São Paulo, v. 12, n.36, 2007.

SISTO, Fermino Fernandes. Dificuldade de aprendizagem em escrita: um instrumento de avaliação (Adape). Dificuldades de aprendizagem no contexto psicopedagógico, p. 190$213,2001$.

SUEHIRO, Adriana Cristina Boulhoça. Dificuldade de aprendizagem da escrita num grupo de crianças do ensino fundamental. Revista de Psicologia da Vetor Editora, v 7, n. 1, p. 59-68, 2006.

THEODORO, Flávia Cristine Medeiros; COSTA, Josenilde Bezerra de Souza; ALMEIDA, Lucia Maria de. Modalidades e recursos didáticos mais utilizados no ensino de ciências naturais e biologia. Estação Científica, v. 5, n. 1, p. 127-139, 2015. 
VIECHENESKI, Juliana Pinto; LORENZETTI, Leonir; CARLETTO, Maria Regina. Desafios e práticas para o ensino de ciências e alfabetização científica nos anos iniciais do ensino fundamental. Atos de pesquisa em educação, v. 7, n. 3, p. 853-876, 2012.

ZABALA, Antoni. A prática educativa: como ensinar. Porto Alegre: Artmed, 1998.

Recebido em: 24 de agosto de 2020.

Aprovado em: 8 de outubro de 2020. 